\title{
INTRODUCTION
}

\section{Of Cooks and Broth}

Some of our first lessons in social psychology come from our parents. As an example, you may have been told, "Too many cooks spoil the broth.” Here we have an early foray into social psychological theory regarding the relationship between group size and quality of the group's output.

Beyond parental theories, we know that this relationship can be complex. Groups bring more minds to an enterprise, but they aren't always better than individuals. For groups to be better, the group needs to communicate well, and it needs to be willing to entertain critique rather than rely on what has been called 'groupthink' that is meant only to keep the group together and happy, possibly at the expense of the quality of the group's work.

In this the second issue of Teaching \& Learning Inquiry, we present papers that represent a social psychologist's dream-an international writing collaborative. Each paper is the product of a fascinating group process. The groups came together from a wide range of institutions and geographic contexts. They took on challenging topics without any previous history of working together. For them to produce the high caliber of paper we have in this issue, the groups needed to listen carefully to all members, to meet the commitments they made to other group members, to have the patience to problem-solve together, to provide thoughtful and sincere critique, and to receive that critique constructively. This is exactly what happened.

Much credit for this must go to the people who provided the overarching leadership for the project, Mick Healey and Beth Marquis. They held true to their collaborative vision, and they knew just how to challenge and support every group in its collective thinking and writing processes.

Most aptly, we learn from the writing team of Billot, West, Khong, Skorobohacz, Roxå, Murray, and Gayle that leadership is only part of the story. There is also followership. Few of us would spontaneously call ourselves followers, yet the success of any collective effort requires that most participants follow well, working with leaders to co-construct group processes and products. Billot and her collaborators apply the notion of followership to teaching and learning in interesting ways.

Indeed, collaboration surfaces as an enduring theme in this issue of TLI, with particular emphasis on collaboration with our students. With so much talk about engaging students in the Scholarship of Teaching and Learning (SoTL), the Felten, Bagg, Bumbry, Hill, Hornsby, Pratt, and Weller group challenges us to collaborate with all students, and not just a select few. To that end, the essay by Spronken-Smith, Brodeur, Kajaks, Luck, 
Myatt, Verburgh, Walkington, and Wuetherick provides an excellent framework for the ways in which collaborations and research opportunities can be seen as vital learning opportunities for our students. Like Felten and his colleagues, the Spronken-Smith team provides very useful examples of what these opportunities look like in actual practice. Further, Healey, Bass, Caulfield, Hoffman, McGinn, Miller-Young, and Haigh direct our thinking about students to include a greater awareness of the many ethical issues surrounding SoTL. They provide a useful framework for thinking through the nature and consequences of these relationships with students.

The article by Matthews, Divan, John-Thomas, Lopes, Ludwig, Martini, Motley, and Tomljenovic-Berube takes a broad look at SoTL literature to determine how much research is focusing on student learning processes as opposed to teaching processes. The answer is not much. They challenge us to adopt this focus more frequently and to look at program-level outcomes, not just single assignment, course, or unit data. Hutchings, Borin, Keesing-Styles, Martin, Michael, Scharff, Simkins, and Ismail offer a rationale and examples for greater collaboration between the SoTL and assessment movements since, despite the differences, they share the same goal of improving student learning.

Williams, Verwoord, Beery, Dalton, McKinnon, Strickland, Pace, and Poole encourage us to collaborate with others at our institutions and to reach across different levels of networks, rather than remaining solitary scholars to working solely within our peer group. The article by Simmons, Abrahamson, Deshler, Kensington-Miller, Manarin, Morón-Garcia, Oliver, and Renc-Roe offers an interesting analysis of the result of these collaborations - and others. They look at how our professional identities change as a result of our involvement with SoTL, especially as we interact more deeply with those outside of our discipline and institution. Ultimately, they argue, our identities become reconstructed in this communal space of SoTL.

Each in its own way, the papers in this issue all argue for the value of collaboration. Moreover, the papers are examples of just how this value can be realized. Many cooks have produced some very good broth. Enjoy!

Gary Poole is the Associate Director of the School of Population and Public Health and a Senior Scholar in the Centre for Health Education Scholarship at the University of British Columbia.

Nancy Chick is Assistant Director of the Center for Teaching and an affiliated faculty member in the English Department at Vanderbilt University. 